\title{
IN VITRO RELEASE OF LECTINS BY Phallusia mamillata HEMOCYTES
}

\author{
Vincenzo Arizza, Nicolò Parrinello and Sandra Schimmenti \\ Institute of Zoology, University of Paiermo, Via Archirafi, 1890123 Palermo, Italy \\ (Submitted April 1990; Accepted January 1991)
}

\begin{abstract}
$\square$ Abstract- $\alpha$-Lactose specific lectins are released from Phallusia mamillata hemocytes during short-term cultures. The molecular weight of the subunits, the immunological cross-reaction and the sugar specificity suggest that the released lectins are similar to those isolated from the sonicated hemocytes. Because lectin release appears to take place independently of active protein synthesis, the possibility exists that lectins are pre-formed, stored in hemocytes and released when in vitro conditions stimulate the cells.
\end{abstract}

$\square$ Keywords-Tunicates; Release; Lectins.

\section{Introduction}

In invertebrates, cellular recognition has been attributed to a protein-carbohydrate molecular mechanism located at the cell surface. Sugar-binding proteins (named lectins or agglutinins) have been found on hemocyte surfaces (1-4) and they are present in the hemolymph of all the examined species, probably involved in nonadaptive immune recognition. In many cases, an opsonic function of humoral lectins has been demonstrated $(5,6)$. In vertebrates, lectins have been identified in several tissues; they are present on the surface of lymphocytes and macrophages and can be involved in

This investigation was supported by grants from the Italian M.P.I. (40\% 1988) and C.N.R. (88 01906.04).

Address correspondence to Nicolò Parrinello. phagocytic functions (7). A possible association between cellular lectin-like activity and recognition processes in the immune response has been suggested (7). Hemocytes of several invertebrates contain (3) and also presumably secrete lectins $(8,9)$.

Tunicates possess lectins in their blood and the humoral lectins studied so far are specific for sialic acid and more frequently, for D-galactosyl residues (10 12). D-galactosyl specific lectins can be present on the hemocyte surfaces of $A s$ cidia malaca (4) and lactose specific lectins on Phallusia mamillata hemocytes (13). Parrinello and Arizza showed that in the blood of Phallusia mamillata two different lectin types exist which have a similar specificity for lactose (13). Humoral lectins, isolated from the serum, consist of a major subunit $(58 \mathrm{Kd})$ and a minor one $(15 \mathrm{Kd})$, probably associated by disulfide linkages. Cellular lectins, isolated from sonicated hemocytes, are formed of two subunits similar in molecular weight ( $36 \mathrm{Kd}$ and $35 \mathrm{Kd}$, respectively) which can occasionally be observed in the SDS-PAGE pattern of purified serum lectins. Lectins of the humoral type or their subunits have not been isolated from hemocytes (13). The aim of the work presented here is to examine if both lectin types derive from lectin-producing hemocytes. Moreover, attempts were made to compare the lectins released from in vitro cultured hemocytes with those purified from serum or hemocytes. 


\section{Material and Methods}

\section{Animals, Blood Collection and Preparation of Cell Suspensions}

Specimens of Phallusia mamillata were collected in the Southern Mediterranean Sea in front of Mazzara del Vallo. The blood was aseptically withdrawn from the heart with a sterile syringe using sterile calcium/magnesium-free artificial sea water (FSW) containing $10 \mathrm{mM}$ EDTA (FSW-EDTA) as anticoagulant. The ratio of blood to FSW was 1:10. The blood was centrifuged at $400 \times g$ for 10 min, the supernatant removed and hemocytes washed three times in sterile FSWEDTA. Cells were counted and adjusted to $1.75 \times 10^{6} \mathrm{cell} / \mathrm{mL}$ in the culture medium.

\section{In Vitro Cell Cultures and Titration of Released Lectins}

Hemocytes were resuspended in the following medium: artificial sea water (SW) which consisted of $60 \%(\mathrm{v} / \mathrm{v})$ of a nutritive medium (RPMI, Leibovitz, M199 or MEM) containing L-glutamine (Flow). RPMI and Medium 199 contain glucose at a concentration of $2000 \mathrm{mg} / \mathrm{L}$ and $1000 \mathrm{mg} / \mathrm{L}$, respectively; Leibovitz medium contains $0.9 \mathrm{~g} / \mathrm{L}$ of galactose; MEM does not contain any sugars. Each of these monosaccharides in solution does not inhibit the Phallusia lectins $(12,13)$. Unless otherwise indicated, M199 was used as nutrient medium in the various experiments. In separate experiments the media were enriched with fetal calf serum (FCS; Flow) at various concentrations $(0-5 \%)$.

The hemocyte suspension was added as $0.08 \mathrm{~mL}$ aliquots to the wells of a sterile 96-well, flat-bottomed culture plate assembly (Falcon Plastic). Cultures were maintained at constant temperature and monitored periodically for contamination. The cell viability was estimated by the trypan blue ( $0.4 \%$ in FSW) exclusion test. At specific intervals, cultures were removed from the wells, centrifuged to remove cells and the supernatant assayed for hemagglutination titers. The microhemagglutination and sugar inhibition tests were carried out in duplicate using rabbit erythrocytes (RE; Sclavo), as previously described (12). The titer was expressed as the reciprocal of the last sample dilution giving clear agglutination. Unless otherwise indicated, the hemagglutinin titer was expressed as a mean of three distinct cultures derived from the same blood sample.

\section{Purification of Cellular and \\ Serum Lectins}

$\alpha$-Lactose specific serum (SL) and cellular lectins (CL) were purified by affinity chromatography on an $\mathrm{HCl}$-treated Sepharose column according to Parrinello and Canicattì (12) and Parrinello and Arizza (13). In brief, to purify cellular lectins, a crude hemocyte extract was prepared by sonication (Sonifer Branson, model B-15P) of hemocytes. The extract was then centrifuged at $27,000 \times$ $g$ for $30 \mathrm{~min}$ at $0^{\circ} \mathrm{C}$ and the supernatant collected. After addition of ammonium sulphate up to $90 \%$ concentration the protein precipitate was extensively dialyzed with phosphate-buffered saline solution (pH 7.4; PBS) and then applied to the column.

\section{Protein Estimation}

Quantitative protein analysis was performed by the method of Lowry et al. (14), using bovine serum albumin (BSA) as a standard.

\section{Sample Concentration}

The samples were concentrated by a Diaflo equipped with a UM2 membrane (Amicon Corp., Livington, MA). 
SDS-Polyacrylamide

Gel Electrophoresis

SDS-PAGE in slab gel was performed according to Laemmli (15); proteins were stained with Coomassie Blue. Gels were calibrated with molecular weight standard proteins (BIO-RAD) and the standard curves obtained as previously described (13). The average of three independent experiments was evaluated.

\section{Preparation of the Immune Serum and Immunoblotting Method}

Preparations of lectins $(310 \mu \mathrm{g} / \mathrm{mL}$ protein content) isolated from the sonicated hemocytes by affinity chromatography were used as antigens. Aliquots (5 $\mathrm{mL}$ ) were injected into a rabbit following previously described (4) methods. Immunoblotting (Western blot) technique was performed as previously described (4). In brief, after the electrophoretic transfer of the ascidian lectins, the nitrocellulose sheets were quenched by repeated washings with $5 \%$ BSA in PBS and then incubated with anti-CL immuneserum. Developing anti-rabbit goat Igs peroxide conjugated (BIO-YEDA) were prepared in $0.1 \% \mathrm{BSA}$ in tris- $\mathrm{NaCl}$; 4-choloronaphtol (CNP) was used as substrate.

\section{Rabbit Immunoglobulin Fractionation}

The rabbit serum was separated from the lipoproteins according to Van Dalen et al. (16). Rabbit immunoglobulins were fractionated from the lipid-free serum, by ion exchange chromatography on a DEAE-Sephacel (Pharmacia) column $(1.6 \times 30 \mathrm{~cm})$ according to Mollison's method (17), as modified by Pharmacia Fine Chemicals (18). Isolated rabbit IgG were about $510 \mu \mathrm{g} / \mathrm{mL}$.

\section{Absorption}

Anti-CL aliquots were absorbed by mixing them $(\mathrm{v} / \mathrm{v})$ with concentrated $(500$ $\mu \mathrm{g} / \mathrm{mL}$ ) lectin solution previously boiled for $5 \mathrm{~min}$ to inactivate the probable lectin-binding capacity with the sugars of the rabbit IgG. The reaction mixtures were incubated at room temperature (r.t.) for $1 \mathrm{~h}$ and 12 at $4^{\circ} \mathrm{C}$ and centrifuged at $27,000 \times g$ for $30 \mathrm{~min}$ at $4^{\circ} \mathrm{C}$. The samples were absorbed twice. The lectins did not react with nonspecific or absorbed rabbit immunoglobulins as shown by immunodiffusion experiments. This suggests that the anti-CL immune serum was specific.

\section{Results}

In Vitro Cell Cultures of Hemocytes in Various Media

Table 1 shows that $1.4 \times 10^{5}$ hemocytes from two separate specimens released lectins in each medium $(80 \mu \mathrm{L})$ in the absence of FCS when tested after $3 \mathrm{~h}$ incubation at r.t. Titer ratios of 1:32 were found using M199, Leibovitz or MEM media to enrich the SW. Longer incubation times increased the release of lectin. The addition of M199 appears to produce the optimal medium so that at $24 \mathrm{~h}$ the

Table 1. Lectin Release from Phallusla mamillata (Specimen n. 1 and n. 2) Hemocytes $\left(7 \times 10^{5}\right.$ cells $\left./ \mathrm{mL}\right)$ Cultured in Different Medla for $3 \mathrm{~h}$ at $20^{\circ} \mathrm{C}$.

\begin{tabular}{lcc}
\hline & \multicolumn{2}{c}{$\begin{array}{c}\text { Hemagglutinating Titer } \\
\text { of Culture Supernatants }\end{array}$} \\
\cline { 2 - 3 } \multicolumn{1}{c}{ Media } & Spec. 1 & Spec. 2 \\
\hline SW & $16-32$ & 8 \\
RPMI & 8 & 2 \\
RPMI-FCS 5\% & 4 & N.D. \\
Leibovitz & 16 & 32 \\
Leibovitz-FCS 5\% & 2 & N.D. \\
M199 & 16 & 32 \\
M199-FCS 5\% & 4 & N.D. \\
MEM & 16 & 32 \\
MEM-FCS 5\% & 4 & N.D. \\
\hline
\end{tabular}


highest titers (1:64) were observed in some of the samples (Table 2).

The addition of FCS in the cell culture medium always reduced the agglutinating activity of the supernatants without increasing hemocyte viability, therefore FCS was not added in the various experiments. The highest FCS concentrations (1-5\%) are the most effective in inhibiting lectin release. Moreover, at concentrations lower than 5\%, after $24 \mathrm{~h}$ incubation time an increase in the lectin titer was observed (Table 3 ).

To check for a possible inhibitory activity of FCS on the lectin erythrocyte binding, those lectins released in FCSfree medium were tested against RE in the presence of FCS. The hemagglutinating titer of FCS-free culture supernatant was not reduced when tested in FCScontaining $(5 \%)$ saline.

The in vitro release of lectins occurs promptly in SW-M199 medium as shown by the repeated hemagglutination tests carried out at 10 -min intervals, up to 90 min. A titer of 8 was observed in the sui pernatant obtained upon centrifugation of the previously washed hemocytes derived from two specimens (n. 9, n. 10); the titer reached the value of 32 upon incubation of the hemocytes from specimen $\mathrm{n} .9$ for $20 \mathrm{~min}$, whereas 16 was the highest value of the titer after 10 -min in-

Table 2. Lectin Release from Hemocytes $\left(7 \times 10^{5}\right.$ cells $/ \mathrm{mL}$ ) of Phallusia mamillata Specimens in SW-M199 (Without Fetal Calf Serum) at Different Incubation Times.

\begin{tabular}{|c|c|c|c|c|c|}
\hline \multirow[b]{2}{*}{ Specimen } & \multicolumn{5}{|c|}{$\begin{array}{l}\text { Hemagglutinating Titer of } \\
\text { Culture Supernatants } \\
\text { (Incubation time (h)) }\end{array}$} \\
\hline & 0 & 3 & 12 & 24 & 48 \\
\hline 1 & N.D. & 32 & 16 & 16 & 64 \\
\hline 2 & N.D. & 32 & 32 & 32 & 32 \\
\hline 3 & N.D. & 32 & 32 & 64 & 128 \\
\hline 4 & N.D. & 16 & 16 & 32 & 64 \\
\hline 5 & 8 & 16 & 16 & 32 & 16 \\
\hline 6 & 8 & 8 & 4 & 4 & 16 \\
\hline 7 & 8 & 16 & 16 & 16 & 16 \\
\hline 8 & 4 & 2 & 4 & 4 & 8 \\
\hline
\end{tabular}

cubation of the cultured hemocytes from specimen $n .10$.

Using the hemocytes from the abovementioned specimens (n. 9, n. 10) the hemagglutinating activity of the cultures supernatants showed a decreasing value when the medium was changed at 10-min intervals: after 3 to 5 washings the titer dropped from 8 to 2 , reaching a value lower than 2 after 8 rinses.

The activity detected in the microculture supernatant did not originate from ruptured hemocytes, because the cells remained viable throughout the incubation period in all of the experiments as determined by trypan blue exclusion tests. The calculated mortality ranged from 0 to $6.3 \%$ (average $2.71 \% \pm 1.48$ $\mathrm{SD}, n=20$ ).

\section{Effect of the Temperature on Lectin Release}

Hemocytes from specimen n. 4 and $n$. 5 were incubated for various periods (in M199-SW nutrient medium) at different temperatures. Lectin release can occur at $0^{\circ} \mathrm{C}$; a $3-\mathrm{h}$ incubation produced an hemagglutinin titer of 16 at 0 to $15^{\circ} \mathrm{C}$. Incubations longer than $3 \mathrm{~h}$ were carried out for each given temperature. During $24 \mathrm{~h}$ at $20^{\circ} \mathrm{C}$ the agglutinin titer increased to 32 , in one culture reaching 64 after $48 \mathrm{~h}$.

\section{Effect of Hemocyte Number on Lectin Release}

The hemagglutinin titer of the culture medium was lowered from 64 to $<2$ proportionally to the decreasing number of the hemocytes (from $1.4 \times 10^{5} /$ well to $2.2 \times 10^{3} /$ well) cultured at $20^{\circ} \mathrm{C}$ for $3 \mathrm{~h}$ (Fig. 1). Similar results were obtained using any of the M199, MEM or Leibovitz culture medium. 
Table 3. Lectin Release from Phallusla mamillata Hemocytes $\left(7 \times 10^{5}\right.$ cells $/ \mathrm{mL}$ ) (Specimen 1) Cultured for 3-24 h at $20^{\circ} \mathrm{C}$ in SW-M199 Enriched with Various Concentration of Fetal Calf Serum (FCS).

\begin{tabular}{cccccrr}
\hline & \multicolumn{5}{c}{$\begin{array}{c}\text { Hemagglutinating Titer of } \\
\text { Culture Supernatants }\end{array}$} \\
\cline { 2 - 7 } $\begin{array}{c}\text { Incubation } \\
\text { Time (h) }\end{array}$ & 5.0 & 1.0 & 0.5 & 0.25 & 0.125 & 0 \\
\hline 3 & $<2$ & 2 & 4 & 4 & 8 & 32 \\
24 & $<2$ & 4 & 8 & 8 & 16 & 64 \\
\hline
\end{tabular}

Carbohydrate Inhibition of the Released Lectins

Of the sugars tested, only lactose and lactulose inhibit the hemagglutinating activity of the released lectins. Fifty $\mathrm{mM}$ was the lowest sugar concentration showing inhibition capacity. No significant inhibition was observed when the monosaccharides D-galactose, L-galactose, D-glucose, L-fucose, D-mannose, the oligosaccharides D-melibiosie, D-raffinose, maltose and the modified sugars 2-deoxy-D-galactose and 2-deoxyD-glucose were used up to a final concentration of $200 \mathrm{mM}$.

\section{Effect of Cycloheximide, $\alpha$-Amanitin} and Actinomycin-D on Lectin Release

The addition of various concentrations $(0.01-0.1 \%)$ of cycloheximide, $\alpha$-amanitin and actinomycin-D did not alter the hemagglutinin titer of the released lectins after 3 to $48 \mathrm{~h}$ incubation at $20^{\circ} \mathrm{C}$.

\section{SDS-PAGE and Immunoblot Analysis} of the Released Lectins

The supernatant of each hemocyte microculture was analyzed by SDS-PAGE

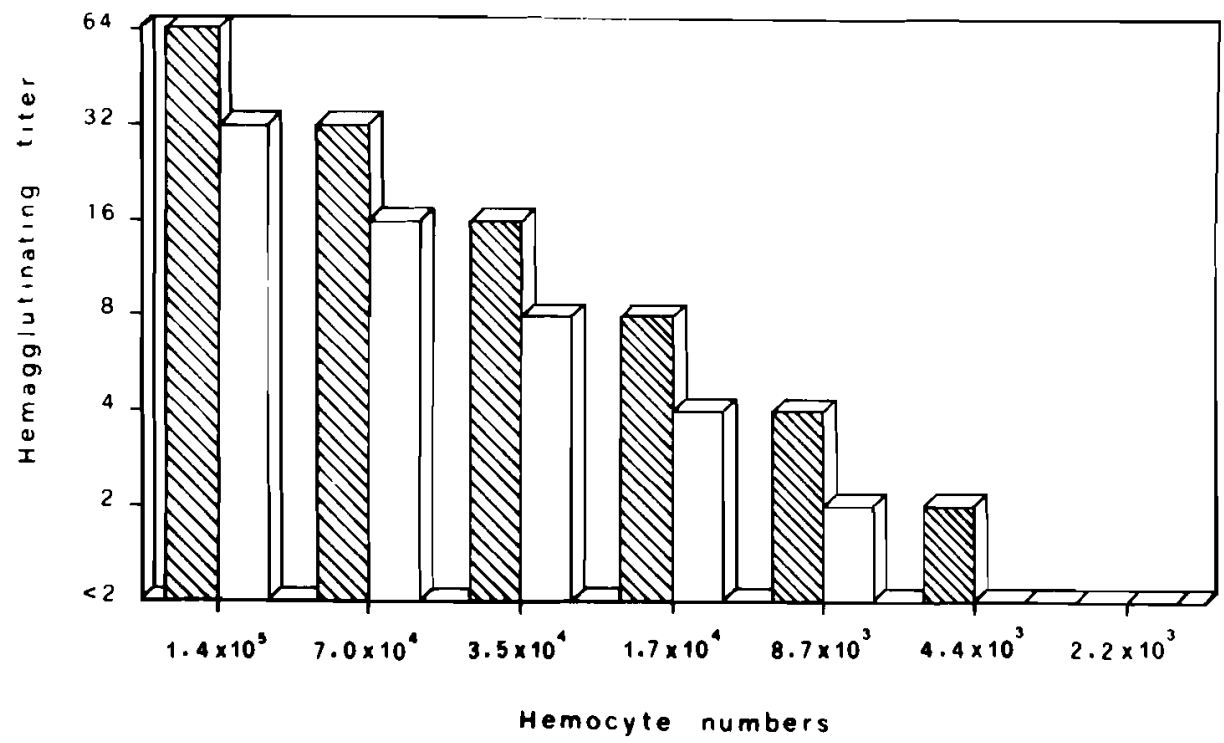

Figure 1. Effect of the number of hemocytes number on lectin release. The hemocytes from specimens $\mathrm{n} .1(\mathrm{~S})$ and $\mathrm{n} .2(\square)$ were individually cultured in SW-M199 for $3 \mathrm{~h}$ at $20^{\circ} \mathrm{C}$. 
and compared with the cellular lectins purified through affinity chromatography of the protein preparation by sonicated hemocytes. The samples were concentrated 10 -fold. Under reducing conditions the protein content $(55.5 \mu \mathrm{g} / \mathrm{mL} \pm$ $2.32 \mathrm{SD}, n=3$ ) of the supernatants obtained after 3-h incubation was resolved into two major components of apparent MWs of $37,533 \pm 858 \mathrm{SD}$ and $35,848 \pm$ 811 SD [Fig. 2(A), line 1]. They correspond to the subunits of the cellular lectin [Fig. 2(A), line 2]. The same pattern characterizes the SDS-PAGE of the supernatants obtained after 24 to $48 \mathrm{~h}$ incubation. Anti-CL immune serum was tested through the Western blot technique with the supernatant obtained from the hemocytes cultures at various times. As shown in Fig. 2(B) the anti-CL polyclonal antibodies react only with the protein components which correspond to the cellular lectins (line 2).

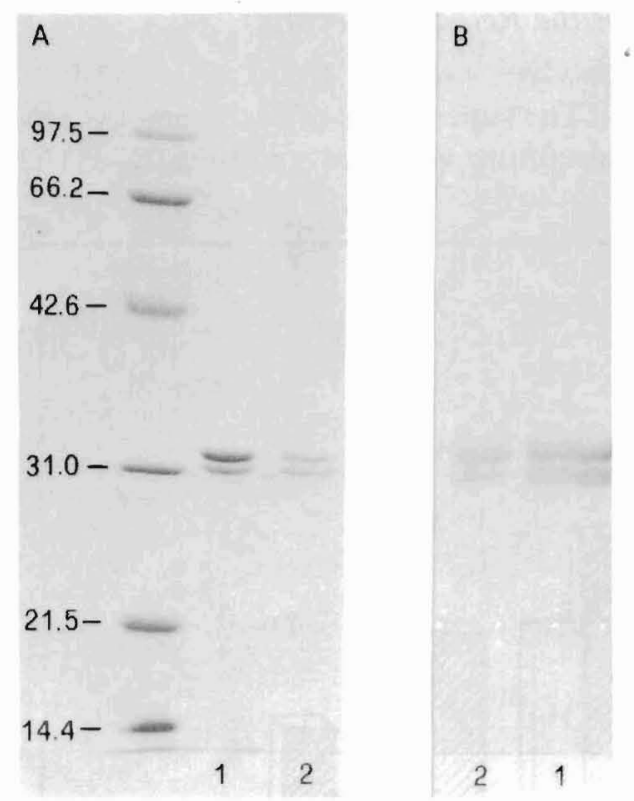

Figure 2. SDS-Polyacrylamide gel electrophoresis $(A)$ and immunoblotting $(B)$ of the supernatants (lines $A 1, B 1)$ from cultured $\left(3 \mathrm{~h}\right.$ at $20^{\circ} \mathrm{C}$ in SW-M199) hemocytes, compared with the isolated cellular lectins (lines A2, B2). The immunoblotting was performed using an anticellular Phallusia mamillata lectin immune serum.

\section{Discussion}

Naturally occurring lectins are present in the plasma from several tunicate species $(1,11,12,19)$. Recently we demonstrated by rosetting and immunofluorescence that lectins can be also present on the surface of Ascidia malaca (4) and Phallusia mamillata (13) hemocytes. Furthermore we were also able to isolate the cellular lectins from Phallusia mamillata hemocytes after sonication (13). Molecular weight determination by SDS-PAGE and immunological methods revealed that serum lectins and cellular lectins are different molecules in spite of their similar sugar specificity. Furthermore, in immunodiffusion assays carried out with anti-SL immune serum, a nonidentity reaction between CL/SL was observed (13).

The source of the SL is not known, whereas the present results suggest that the CL can be released from the hemocytes cultured in vitro. From the molecular weight of the subunits the released lectins appear to be of the CL type. The immunological cross-reaction in Western blot analyses and the sugar specificity of the CLs are in agreement with this suggestion. The presence of a lactoselactulose binding site can thus be assumed.

Naturally occurring lectins of the CL types can occasionally be identified in the serum, depending on the samples used, by blue Coomassie staining of SDS-PAGE. In some cases they were observed when the serum was concentrated several times. Such results indicate a further difference from the serum lectins. It is surprising that lectins of SL type are not found in the culture medium whereas a relatively high titer of CL was constantly observed. The possibility exists that in the whole blood, various factors control the $\mathrm{CL}$ release and that the absence of accessory factors in the culture media and/or the in vitro conditions 
might stimulate the hemocytes to release CLs.

It seems likely that cellular lectins are not continuously released by hemocytes into the circulation; rather they are released in the course of collection and centrifugation procedures. This would suggest that secretion is triggered when hemocytes come into contact with foreign substances, that is, the walls of syringes or centrifuge tubes. This assumption is supported by the occurrence of lectin release from hemocytes immediately after their pelletting upon centrifugation, and their continuous secretion prevalently during short-term culture. Following contact with foreign material the release from hemocytes was rapid and increased within 10 to $20 \mathrm{~min}$. Moreover, the hemagglutinating activity of supernatants obtained from repeated washing of hemocytes declines after several changes of the medium.

In a previous paper (13), we showed that by mixing hemocytes and RE three reactions demonstrating release of lectins could be obtained in a few minutes: (1) clumps of aggregates composed of hemocytes and REs which probably are secretory rosettes; (2) clumps of eryth- rocytes agglutinated by the released lectins; (3) rosettes formed by hemocytes with not less than three erythrocytes attached. The hemocyte types were not identified.

In the hemocyte culture conditions which we used, lectin release appears to be independent of active protein synthesis. The cycloheximide, $\alpha$-amanitin and actinomycin-D inhibitors of protein synthesis at various levels did not affect lectin release despite the long incubation time (48 h). This is in accordance with the lectin release observed when hemocytes were maintained at $0^{\circ} \mathrm{C}$. This anomalous behaviour cannot be explained based on our experiments, in fact, usually exocytotic processes are inhibited by low temperatures. The possibility exists that lectins are preformed and stored in hemocytes and released when in vitro conditions stimulate them.

The SLs could originate from a totally different source or could be released from hemocytes in the presence of plasma releasing factors. However since both SL and CL have similar binding sites, it seems likely that they have similar functional roles.

\section{References}

1. Vasta, G. R.; Cheng, T. C.; Marchalonis, J. J. A lectin on the hemocyte membrane of the oyster (Crassostrea virginica). Cell. Immunol. 88:475-488; 1984.

2. Amirante, G. A. Production of heteroagglutinins of Leucophaea maderae. Experientia. $32: 526-528 ; 1976$.

3. Amirante, G. A.; Mazzalai, F. G. Synthesis and localization of hemagglutinins in hemocytes of the cockroach Leucophaea maderae L. Dev. Comp. Immunol. 2:73-740; 1978.

4. Parrinello, N.; Arizza, V. D-galactose binding lectins from the tunicate Ascidia malaca: subunit characterization and hemocyte surface distribution. Dev. Comp. Immunol. 12:495$507 ; 1988$.

5. Cheng, T. C.; Marchalonis, J. J.; Vasta, G. R. Role of molluscan lectins in recognition processes. In: Cheng E., editor. Recognition proteins, receptors and probes: invertebrates. New York: Alan R. Liss; 1984; 1-15.
6. Renwrantz, L.; Stahmer, M. Opsonizing properties of an isolated hemolymph agglutinin and demonstration of lectin-like recognition molecules at the surface of hemocytes from Mytilus edulis. J. Comp. Physiol. 149:535-546; 1983.

7. White, S. L. Role of lectins in immune recognition. In: Olden, K.; Parent, J. B., editors. Vertebrate lectins. New York: Van Nostrand Reinhold; 1986; 182-194.

8. Stein, E. A.; Cooper, E. L. In vitro agglutinin production by hearthworm leucocytes. Dev. Comp. ImmunoI. 12:531-547; 1988.

9. Leippe, M.; Renwrantz, L. Release of cytotoxic and agglutinating molecules by Mytilus hemocytes. Dev. Comp. Immunol. 12:297308; 1988.

10. Vasta, G. R.; Marchalonis, J. J. Distribution, specificity and macromolecular properties of tunicate plasma lectins. In: Cohen $E_{\text {, }}$ editor. Recognition proteins, receptors, and probes: 
invertebrates. New York: A. R. Liss; 1984; 125-141.

11. Parrinello, N.; Canicattì, C. Carbohydrate binding specificity and purification by biospecific affinity chromatography of Ascidia malaca Traust. hemagglutinins. Dev. Comp. Immunol. 6:53-64; 1982.

12. Parrinello, N.; Canicattì, C. $\alpha$-Lactose binding hemagglutins from the ascidian Phallusia mamillata (Cuv.). Biol. Bull, 164:124-135; 1983.

13. Parrinello, N.; Arizza, V. Sugar specific cellular lectins of Phallusia mamillata hemocytes: purification, characterization and evidences for cell surface localization. Dev. Comp. Immunol. 13:113-121; 1989.

14. Lowry, O. H.; Rosembrough, N. J.; Farr, A. L.; Randall, R. J. Protein measurement with the folin phenol reagent. J. Biol. Chem. 193:256-275; 1951.

15. Laemmli, U. K. Cleavage of structural proteins during the assembly of the head of bacteriophage T4. Nature. 227:680-685; 1970.

16. Dalen, A. van; Seijen, H. G.; Gruber, M. Isolation and same properties of rabbit IgM immunoglobulins. Biochim. Biophys. Acta. 147:421-426; 1967.

17. Mollison, P. L. Blood transfusions in clinical medicine, Oxford: Blackwell Scientific Publications; 1975 .

18. Pharmacia Fine Chemicals Immunoglobulin fractionation by ion exchange chromatography. Separation News. 5:1-3; 1980.

19. Parrinello, N.; Patricolo, E. Erythrocyte agglutinins in the blood of certain ascidians. Experientia. 31:1092-1093; 1975. 